\title{
Enzymatic Solubilisation and Degradation of Soybean Fibre Demonstrated by Viscosity, Fibre Analysis and Microscopy
}

\author{
Jonas Laukkonen Ravn ${ }^{1}$, Helle Juel Martens ${ }^{2}$, Dan Pettersson ${ }^{1} \&$ Ninfa Rangel Pedersen ${ }^{1}$ \\ ${ }^{1}$ Novozymes A/S, Krogshoejvej 36, 2880 Bagsværd, Denmark \\ ${ }^{2}$ University of Copenhagen, Thorvaldsensvej 40, 1871 Frb, Denmark \\ Correspondence: Ninfa Rangel Pedersen, Novozymes A/S, Krogshoejvej 36, 2880 Bagsværd, Denmark. E-mail: \\ nrp@novozymes.com
}

$\begin{array}{lc}\text { Received: May 15, } 2015 & \text { Accepted: June 16, } 2015 \quad \text { Online Published: August 15, } 2015 \\ \text { doi:10.5539/jas.v7n9p1 } & \text { URL: http://dx.doi.org/10.5539/jas.v7n9p1 }\end{array}$

\begin{abstract}
The effect of a commercial multienzyme product obtained by fermentation from Aspergillus aculeatus on soybean and soybean meal was investigated using viscosity measurements, dietary fibre component analysis and different microscopy techniques utilizing histochemical dyes and antibody labelling. The results obtained demonstrated a strong viscosity reducing effect of the enzyme preparation on soluble galactomannan and xyloglucan polysaccharides and in addition non-starch polysaccharide analysis demonstrated a notable solubilisation of all polysaccharide constituents. The degradation of these components as native integral parts of cell walls upon exposure to the enzyme was visualized with microscopy. Two histochemical dyes, coriphosphine $\mathrm{O}$ and alcian blue were successfully used to follow pectin solubilisation after enzyme treatment. Commercial antibodies recognizing specific components of pectin and hemicellulose components of soybean cell wall were also used to visualize several enzyme activities in the commercial enzyme preparation The challenges of using commercial antibodies elicited from a given plant source to detect similar epitiopes on another plant source are also discussed. Non-starch polysaccharide analysis of the insoluble dietary fibre constituents before and after enzyme treatment corroborated the visualized mode of action demonstrated by microscopy. The combination of techniques provided visual and quantitative measurements of the solubilisation and degradation of hemicellulose pectic soybean cell wall components as part of the undesirable antinutrients in animal feed.
\end{abstract}

Keywords: enzymes, SBM, NSP, viscosity, pectic polysaccharides, hemicelluloses, microscopy

\section{Introduction}

Due to EU legislation that limits the use of meat and bone meal as a protein supplement in animal production since early 2001, a bigger market has been created for soybean meal (SBM) and other plant protein based ingredients (Brookes, 2001). The by-product meals of soybean (Glycine max), canola or rapeseed (Brassica napus), sunflower (Helianthus annuus) and palm kernel (Elaeis guineensis) obtained after industrial oil extraction are major components in livestock feed. SBM, due to its high content of good quality protein (Friedman \& Brandon 2001) dominates the global feed market for vegetable protein meals making it an excellent ingredient in feed formulations to especially poultry and pigs.

The composition and nutritive value of oilseed meals depend on the cultivar and growing conditions as well as the processing conditions (Brookes 2001; Karr-Lilienthal et al., 2005). Oilseeds contain a variety of anti-nutritional factors (ANFs) e.g. serine protease inhibitors and lectins, which have toxic properties in monogastrics (Nahashon \& Kilonzo-Nthenge, 2011) as well as non-starch polysaccharides (NSPs), which may influence digestion and absorption since monogastrics do not have endogenous enzymes that enable them to break down and digest the complex plant cell wall lattices (De Vries et al., 2012). Therefore perhaps the most important factor that influences the nutritive value of oilseed meals are the indigestible acidic and neutral NSPs originating from the plant cell walls. In addition, there are also indigestible low molecular weight sugars such as raffinose and stachyose originating from the endosperm. The cell walls of soybean and other dicotyledons are categorized as type I cell walls consisting of rhamnogalacturonans, classified as pectin polysaccharides, cellulose and hemicelluloses (e.g. xyloglucans and mannans). There is about 6\% pectin in SBM, 9\% in rapeseed meal and $5 \%$ in sunflower meal (Malathi \& Devegowda, 2001). Rhamnogalacturonan has a main chain of galacturonic acid interlaced with rhamnose and with side chains of galactose and arabinose residues (Huismann et al., 1998). 
Pectins remain largely intact during the digestion process in the small intestine, increasing digesta viscosity and reducing digestion and absorption of the nutrients (Langhout \& Schütte, 1996).

Xyloglucan is a highly water soluble hemicellulose (Fry, 1989) and an increasing chain length of the backbone results in increasing viscosity (Gloster et al., 2007). Another viscous polysaccharide is $\beta$-mannan which inhibits insulin secretion in swine (Leeds et al., 1980; Sambrook \& Rainbird, 1985), suggesting a deleterious effect on energy.

The application of feed NSP degrading enzymes to improve digestion, overcome anti-nutritive effects and hereby increase animal welfare and generate uniform livestock is well acknowledged today. Recent estimates indicate that feed enzymes saved the global feed market US\$ 3-5 billion per year (Cowieson \& Adeola, 2011). Choosing the appropriate enzyme product depends on the constituents of the plant material in the diet. Using enzymes to reduce the water holding capacity of the material may have a positive influence on nutrient absorption. In addition, liberation of galactose monomers from the degradation of the pectin fraction and the raffinose series may also improve the metabolizable energy value of soybean (Slominski, 1994; Ao et al., 2010; Pettersson \& Pontoppidan, 2013). A multienzyme product from Aspergillus aculeatus, sold as a commercial solution to maximize energy utilization of vegetable protein sources in animal production, contains a unique blend of hemicellulases and pectinases. However, a comprehensive study of the active enzymes in the product is not publically available.

The objective of the current study is to demonstrate the impact of the commercial multienzyme product on the NSPs present in soybean by viscosity measurements, NSPs analyses and the use of microscopy and labelling techniques (antibodies and histochemical staining).

\section{Method}

\subsection{Plant Material}

SBM, in the form of flakes, were obtained from solvent extracted, defatted and toasted soybean originating from Argentina, Brazil, India or US and procured from DSM, Australia. Organic whole soybean seeds were obtained from a local health store in Copenhagen, Denmark.

\subsection{Enzyme}

RONOZYME $^{\circledR}$ VP, is a classical multienzyme product obtained by fermentation of a wild type organism (Aspergillus aculeatus) and available from DSM Nutritional Products, Basel, Switzerland as a liquid commercial enzyme product. It is declared to have an endo-glucanase activity of $120 \mathrm{FBG} / \mathrm{mL}$ (Fungal Beta-Glucanase units $/ \mathrm{mL}$ ) but is also known to contain various hemicellulase and pectinase activities. The product is stable in gut environments under low $\mathrm{pH}$ and remains active in the small intestine and was used in the current studies. The activity of a pure mannanase (experimental) was also studied using fluorescence microscopy and compared to the mannanase activity in the commercial product.

\subsection{Viscosity}

Viscosity studies were conducted using a pipetting workstation, Hamilton, with eight microprocessor-controlled pipetting channels that are analogous to manual pipettes. It is capable of pressure sensing during aspiration and dispensing of solutions. The viscosity pressure (ViPr) assay displays a linear correlation between pressure measured $(\mathrm{Pa})$ and kinematic viscosity. During the complete aspiration and dispensing process the air displacement is continuously monitored in intervals of $10 \mathrm{~ms}$ by a pressure sensor to verify an uninterrupted substrate flow. Pressure measured in this work is defined as viscosity determined in relation to the ViPr assay. A decrease in viscosity would indicate enzymatic degradation of a viscous polymer into smaller less viscous oligomers.

\subsection{Substrates for Viscosity}

The substrates galactomannan and xyloglucan were obtained from Megazymes, Ireland. A solution of galactomannan $(0.5 \mathrm{~g} / 100 \mathrm{~mL})$ and xyloglucan $(1 \mathrm{~g} / 100 \mathrm{~mL})$ was prepared in $0.1 \mathrm{M}$ sodium acetate buffer, $\mathrm{pH} 5$.

Substrate $(250 \mu \mathrm{L})$ was pipetted in a 96 well microtiter plate (MTP) and incubated with $20 \mu \mathrm{L}$ of the enzyme product, or buffer (control), at $40{ }^{\circ} \mathrm{C}$ for 30 mins with stirring. A Hamilton STARLET liquid handler (Hamilton) was programmed to measure pressure during aspiration and dispensation of samples with measurements taken at 15 minute intervals.

\subsection{NSP Analyses for Solubilisation of SBM Cell Walls}

Triplicate samples of SBM, without enzyme supplementation, or with the addition of the multicomponent 
enzyme at a dose of $15625 \mathrm{FBG} / \mathrm{kg} \mathrm{SBM}$ were incubated at $40{ }^{\circ} \mathrm{C}$ for $4 \mathrm{~h}$ in a $0.1 \mathrm{M} \mathrm{NaAc}$ buffer containing 5 $\mathrm{mM}$ calcium. Samples were centrifuged at $2500 \mathrm{xg}$ for 10 minutes and the supernatant was discarded. The remaining pellet containing the insoluble cell walls was washed twice by re-suspending the sample in the acetate buffer and discarding the supernatant after centrifugation. Following this procedure the pellet was dried and cellulose was solubilised with $12 \mathrm{M}$ sulphuric acid and the sample was analysed for non-starch polysaccharide residues (Theander et al., 1995).

\subsection{Microscopy: Embedding and Sectioning}

Pieces of approx. $3 \times 3 \times 6 \mathrm{~mm}$ whole soybean seeds (containing seed coat, aleurone layer and storage cotyledons) were fixed in Karnovsky's fixative to terminate ongoing biochemical reactions in the plant cells. Samples were washed in $0.1 \mathrm{M}$ cacodylate buffer $\mathrm{pH} 7.3$ and demineralized water and dehydrated in a graded series of acetone before infiltration with Spurr's resin (Spurr, 1969). Infiltrated Spurr's samples were incubated at $50{ }^{\circ} \mathrm{C}$ for 2 days in a block for solidification. Semithin $(2 \mu \mathrm{m})$ cross sections were produced on a Super Nova KL 1500 electronic microtome (Reichert-Jung, Austria).

Small flakes of SBM as well as pieces of whole soybean seeds were fixed in Karnovsky's fixative washed in 0.1 $\mathrm{M}$ cacodylate buffer $\mathrm{pH} 7.3$ and demineralized water and dehydrated in a graded series of ethanol before infiltration in melted paraplast (paraffin) at $60{ }^{\circ} \mathrm{C}$ using Histochoice clearing agent (Sigma-Aldrich). Paraffin-embedded samples were sectioned into 7-10 $\mu \mathrm{m}$ thick sections on a 2030 Biocut microtome (Reichert-Jung, Austria). De-paraffination was done with Histochoice and a graded series of ethanol.

\subsection{Staining}

Spurr's sectioned samples and de-paraffinated SBM were stained with $0.03 \%$ (aq) coriphosphine $\mathrm{O}$ for 10 min. Other sections of de-paraffinated SBM were stained with $0.01 \%$ alcian blue $8 \mathrm{GX}(\mathrm{aq})$ at $\mathrm{pH} 2.5$ dye for 20 mins (Whiteman, 1973).

\subsection{Enzyme Treatment}

Thick $(7-10 \mu \mathrm{m})$ sections of de-paraffinated SBM and whole seeds were treated with the enzyme product or the experimental mannanase by adding a $\sim 500 \mu \mathrm{L}$ droplet to the de-paraffinated section directly on the glass side. Enzyme treatments lasted 3 hours at $39^{\circ} \mathrm{C}$ under slight stirring in darkness using either a $\times 100(0.120 \mathrm{FBG} / \mathrm{mL})$ or a $\times 500(0.024 \mathrm{FBG} / \mathrm{mL})$ dilution of the enzyme product.

The commercial enzyme product was diluted in $100 \mathrm{mM}$ acetate buffer $\mathrm{pH} 5$ containing $5 \mathrm{mM}$ calcium acetate. Experiments using SBM, treated with buffer alone (control without enzyme) for 3 hours under the same conditions were also conducted. After 3 hours incubation the samples were washed with deionized water.

\subsection{Immunocytochemistry}

Immunocytochemistry was performed on acetate buffer treated (control) and enzyme treated slides containing SBM by blocking samples with 5\% skimmed milk in 1x PBS for 1 hour and washing at least three times in PBS buffer followed by incubation with 10-fold dilutions of appropriate rat monoclonal antibodies (LM5, LM6, LM20, LM21 and LM25) diluted in 5\% skimmed milk in 1x PBS for 1 hour. Samples were subsequently incubated in a 300-fold dilution of anti-rat IgG linked to an Alexa-555 fluorophore for $1 \frac{1 / 2}{\mathrm{~h}}$ and washed in PBS buffer. Citiflour AF1 (Agar Scientific, UK) anti-fading agent was added to avoid bleaching of fluorescence signal (Jones et al., 1997). For feasibility, two separate microscope slides were needed for each specimen for control and enzyme treatment, respectively. A negative control labelling only with the secondary antibody was made by addition of only secondary antibody for $2 \mathrm{~h}$ after blocking with $5 \%$ milk and washing with PBS buffer. Antibodies targeting the different cell wall components were purchased from Plant Probes, UK (Retrieved April 25, 2015, from http://www.plantprobes.net/index.php).

\subsection{Light and Fluorescence Microscopy}

Images were recorded in a Nikon Eclipse 80i FM fluorescence microscope (Japan). A V-2A UV excitation filter $(380-420 \mathrm{~nm})$ with LP450 emission was used for excitation of the fluorescent dye coriphosphine $\mathrm{O}$ as well as autofluorescence from protein bodies. Alcian blue signal was recorded in brightfield mode.

\subsection{Confocal Microscopy}

Confocal images of immunolabelled samples were acquired from sections of SBM flakes using a Leica CLSM SP2 microscopy (Heidelberg). A 20x water-immersion objective was used for all images. An excitation laser line at $543 \mathrm{~nm}$ (green) and an emission spectrum from 623-670 nm was used to monitor the Alexa-555 fluorescein-signal from the immunolabelling. This emission spectrum was designated a red color in the LAS AF Lite (Leica) software. An excitation laser line at $488 \mathrm{~nm}$ (blue) and an emission spectrum from 506-523 nm was 
used to monitor the autofluorescence from protein globules. This emission spectrum was designated a green color. The images were processed in the LAS AF Lite (Leica) software. Autofluorescence was tested using the same microscope settings as well as a control for unspecific binding of the secondary antibody in soybean.

Contrast adjustments were carried out to improve clarity of images but did not alter overall appearance. Final image processing, cropping and mounting of the images were done with Adobe Photoshop CS5 and Illustrator CS5.

\section{Results}

\subsection{Viscosity}

Within 30 mins a significant viscosity reduction was observed compared to the control without enzyme when adding the commercial product to viscous xyloglucan and galactomannan solutions (Figure 1), indicating the degradation of above polymers due to the presence of xyloglucanases and galactomannanases in the product.

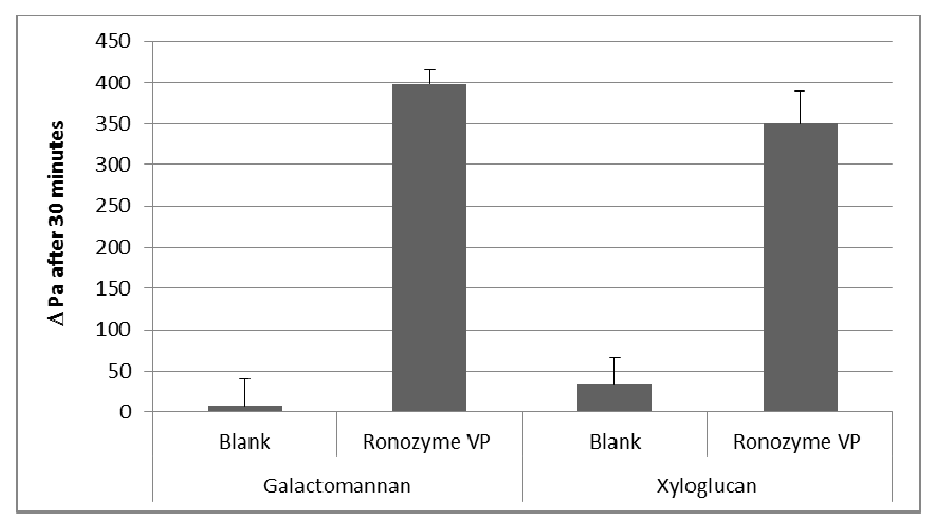

Figure 1. Viscosity reduction

Note. Viscosity reduction $(\triangle \mathrm{Pa})$ after 30 mins of incubation at $40{ }^{\circ} \mathrm{C}$ of galactomannan $(0.5 \mathrm{~g} / 100 \mathrm{~mL})$ and xyloglucan solutions $(1 \mathrm{~g} / 100 \mathrm{~mL})$ supplemented with the commercial enzyme product (Ronozyme VP). Standard deviations are indicated by error bars.

\subsection{In vitro Solubilisation of SBM Cell Walls}

Analysis of the in vitro solubilisation of the insoluble cell walls in SBM revealed an overall statistically significant solubilisation of the sum of all non-starch polysaccharides (Table 1) with a total disappearance of about $31 \%$ (from a total NSP content of $17.1 \%$ to $11.7 \%$ ). For individual neutral sugar residues major and statistically significant disappearances were observed for arabinose, galactose and glucose with reductions in insoluble sugar residues of approximately 36,36 and $39 \%$, respectively. A statistically significant and strong numerical reduction of rhamnose by $35 \%$ was also observed. The solubilisation of xylose and mannose was about 18 and 14\%, respectively, and although not statistically significant this still may represent a considerable solubilisation of else insoluble constituents that are part of major polysaccharide structures such, e.g. xyloglucans or galactomannans. For the insoluble acid pectins, analysed as uronic acid residues, a solubilisation of about $22 \%$ was detected.

Table 1. Dry matter content (\%) of insoluble cell wall constituents provided as non-starch polysaccharide residues in SBM after incubation at $40^{\circ} \mathrm{C}$ for 4 hours in a buffer system $(\mathrm{pH} 5,0.1 \mathrm{M}$ sodium acetate buffer with $5 \mathrm{mM}$ calcium) without or with supplementation of a commercial multicomponent enzyme obtained from Aspergillus aculeatus

\begin{tabular}{lllllllll}
\hline & \multicolumn{7}{c}{ Insoluble non-starch polysaccharide residues (\% of dry matter) } \\
\cline { 2 - 8 } & Rhamnose & Fucose & Arabinose & Xylose & Mannose & Galactose & Glucose* & Uronic acids \\
\hline Control & $0.52 \mathrm{~A}$ & $0.36 \mathrm{~A}$ & $2.22 \mathrm{~A}$ & $0.91 \mathrm{~A}$ & $0.56 \mathrm{~A}$ & $5.03 \mathrm{~A}$ & $3.86 \mathrm{~A}$ & $3.6 \mathrm{~A}$ \\
Enzyme & $0.34 \mathrm{~B}$ & $0.27 \mathrm{~B}$ & $1.42 \mathrm{~B}$ & $0.75 \mathrm{~A}$ & $0.48 \mathrm{~A}$ & $3.23 \mathrm{~B}$ & $2.36 \mathrm{~B}$ & $2.8 \mathrm{~B}$ \\
\hline
\end{tabular}

Note. *Glucose value includes cellulose; $\mathrm{AB}$ : Average values within a column not sharing a capital letter differ significantly $(\mathrm{P}<0.05)$. 


\subsection{Cell Wall Solubilisation Monitored by a Fluorescent Dye and a Basic Dye}

To help identify intact cell wall constituents whole soybean tissue was included (Figures 2A-2F). Even though the oil seed is extensively processed, SBM still showed a quite well preserved, although compressed, microstructure (Figure 2G).
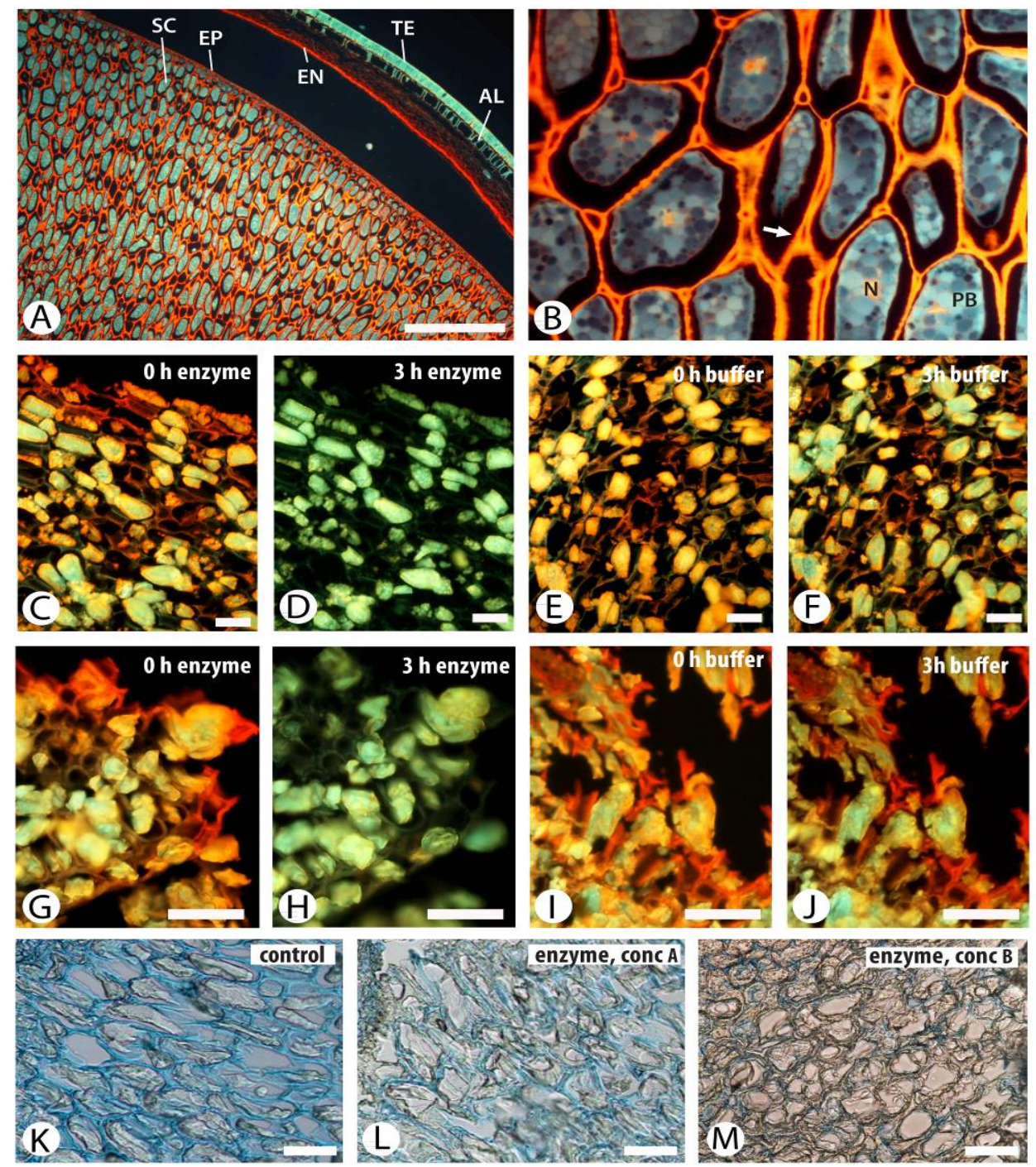

Figure 2. Microscopy of a solubilisation effect of pectic soybean polysaccharides

Note. The effect of the commercial enzyme product treatment (Ronozyme VP, $0.120 \mathrm{FBG} / \mathrm{ml}$ ) on soybean tissue visualized as a reduction in coriphosphine $O$ staining intensity and in alcian blue staining. A and $\mathrm{B}$ : Semithin sections of resin-embedded soybean showing the general seed microstructure of intact soybean tissue with pectin-rich regions labelled with orange fluorescence. The turquoise-blue color is autofluorescence from protein bodies within the storage cotyledons and from lignified cell walls. Note that the outer cell layers have become detached from the cotyledon. C and D: De-paraffinated thick sections of intact whole soybean seed tissue after 0 hours (C) and 3 hours (D) of enzyme treatment. E and F: De-paraffinated thick sections of whole soybean seed after 0 hours (E) and 3 hours (F) of buffer treatment (negative control). G and H: De-paraffinated thick sections of SBM after 0 hours $(\mathrm{G})$ and 3 hours $(\mathrm{H})$ of enzyme treatment. I and J: De-paraffinated thick sections of SBM after 0 hours (I) and 3 hours (J) of buffer treatment (negative control). K-M: De-paraffinated thick sections of SBM after 0 hours (K), after 3 hours (L) using a $0.024 \mathrm{FBG} / \mathrm{ml}$ commercial enzyme conc. and after 3 hours (M) using a $0.120 \mathrm{FBG} / \mathrm{ml}$ commercial enzyme conc. $\mathrm{SC}$ - storage cotyledons, TE - testa (seed coat), EP - epidermis, $\mathrm{EN}$ - endosperm, $\mathrm{AL}$ - aleurone layer, $\mathrm{PB}$ - protein bodies, $\mathrm{N}$ - nucleus, arrow - pectin-rich region. $\mathrm{Bar}=500$ $\mu \mathrm{m}(\mathrm{A}) . \mathrm{Bar}=100 \mu \mathrm{m}(\mathrm{B}-\mathrm{G})$. 
Spherical protein bodies, showing blue/turquoise autofluorescence from the aromatic amino acids, were packed tightly together within storage cotyledon cells (Figure 2B).

Enzyme incubations of de-paraffinated sections of whole soybean resulted in an almost complete disappearance of yellow/orange color, indicating pectinase activity resulting in solubilisation and disappearance of pectic polysaccharides (Figure 2D) compared to the staining before enzyme treatment (Figure 2C). Control treatments in acetate buffer (Figures 2E-2F) showed only very slight disappearance of yellow/orange color. Intact soybean tissue (Figure 2C) displayed structural resemblance to SBM (Figures 2G-2M) and similar results could be obtained with enzyme treatment using de-paraffinated SBM (Figure 2H). Again SBM control samples, treated in acetate buffer under same conditions for $3 \mathrm{~h}$, showed insignificant decrease in coriphoshine $\mathrm{O}$ staining (Figures 2I-2J).

The pectin degradation in SBM was further documented by loss of blue staining from the basic pectin dye alcian blue in SBM treated with enzyme (Figures 2K-2M). Enzyme incubations resulted in significant disappearance of blue color using both a $0.024 \mathrm{FBG} / \mathrm{mL}$ concentration (Figure $2 \mathrm{~L}$, conc. A) and a higher dose at $0.120 \mathrm{FBG} / \mathrm{mL}$ (Figure 2M, conc. B) compared to the acetate buffer treated control (Figure 2K) showing a dose dependency of alcian blue staining.

Figure 4 shows the controls for pectin specificity of the dyes. As a negative control it is shown that cell walls of barley grain endosperm neither stain with coriphosphine $O$ (Figure 4B) nor with alcian blue (Figure 4D) as monocot cereals contain low amounts of pectin. As a positive control, cell walls of the dicot lupin seed storage cells reacted strongly to coriphosphine O (Figure 4C) and alcian blue (Figure 4E).

\subsection{Cell Wall Solubilisation Detected with Monoclonal Antibodies}

Monoclonal antibodies developed against a variety of cell wall fibre components were applied to de-paraffinated sections of SBM incubated beforehand with either acetate buffer (control) or enzyme (Figure 3). Images were recorded in a confocal microscope displaying the Alexa-555 fluorescein signal in red. The protein autofluorescence signal was displayed in yellow as a result of an overlay of green and red emissions from both the blue and green laser line.

After enzyme treatment, the monoclonal antibody signal was significantly reduced or not detectable (images on the right hand side column) compared to slides incubated in acetate buffer alone (images on the left hand side column). This indicates a reduction in carbohydrate epitopes e.g. galacturonan, xylogalacturonan, xyloglucan, mannan or galactan.

The monoclonal antibodies LM20 and LM19, which recognize galacturonan and homogalacturonan epitopes (Figures $3 \mathrm{~A}$ and $3 \mathrm{C}$ ), respectively, bound to the middle lamella region and around cell junctions. The signal from LM20 and LM19 (Figures 3A and 3C) almost disappeared following enzyme treatment (Figures 3B and 3D). However, a vague LM19 signal could be noted (Figure 3D). The LM19 has been described as a monoclonal antibody against apple pectin (Verhertbruggen et al., 2009) but can also bind to SBM (Figure 3C).

LM21 a mannan-directed monoclonal antibody, (Marcus et al., 2010), recognized and bound effectively to the mannan in the cell walls in SBM in a continuous punctuated manner (Figure 3E) a pattern also observed previously in other dicots (Ordaz-Ortiz et al., 2009). Upon treatment with enzyme, the LM21 binding disappeared (Figure 3F) seen as a lack of red signal color due to degradation of mannan. Treatment with pure monocomponent experimental mannanase provided the same results (data not shown).

Immunofluorescence labelling with monoclonal antibody LM25 towards xyloglucan (Pedersen et al., 2012) bound abundantly to cell walls lining intercellular spaces on the cytoplasmic side of the cell wall (Figure 3G). On treatment with enzyme, the LM25 binding was significantly lowered (Figure 3H).

The monoclonal antibody LM5 bound to galactan (Figure 3I) and monoclonal antibody LM6 bound to arabinan (Figure 3K) in SBM, may indicate the presence of side chains of the pectic rhamnogalacturonan polymer. The treatment with the commercial enzyme degradation of galactan and arabinan caused a disappearance in the monoclonal antibody LM5 signal (Figure 3J) as well as in the monoclonal antibody LM6 signal (Figure 3L).

Figure 4A shows the negative control using only the secondary antibody Alexa-555 showing no unspecific binding of the secondary antibody to SBM, i.e. the observed signal is due to binding of the secondary antibody to the primary antibody. 

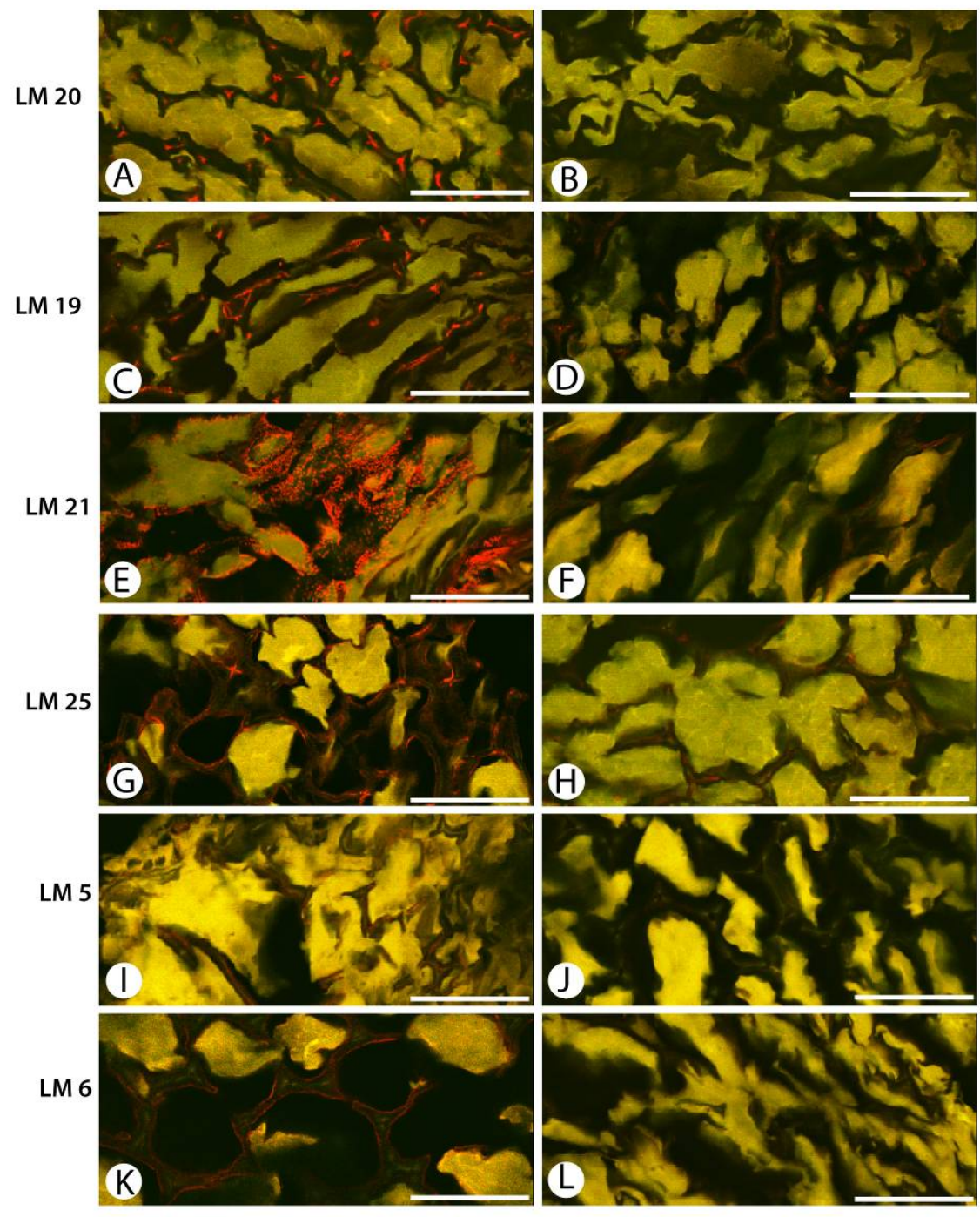

Figure 3. Confocal microscopy of antibody labelled SBM treated without or with enzyme product

Note. The specific degradation of pectin homogalacturonan epitopes, $\beta-1,4-m a n n a n, x y l o g l u c a n$, galactan and arabinan by the commercial product as detected by indirect immunofluorescence within de-paraffinated thick sections of SBM using monoclonal antibodies. A-D Immunolabelling and binding of LM20 and LM19 (antibodies to pectin homogalacturonan) to SBM. LM20-labelled SBM control sample (A) treated in 3 hours in buffer and a LM20-labelled SBM sample (B) after 3 hours treatment with 0.024 FBG/ml enzyme. LM19-labelled SBM control sample (C) treated 3 hours in buffer and a LM19-labelled SBM sample (D) after 3 hours treatment with $0.024 \mathrm{FBG} / \mathrm{ml}$ commercial enzyme. E-H: Immunolabelling and binding of LM21 and LM25 (antibodies to the hemicelluloses $\beta-1,4-$ mannan and xyloglucan, respectively) to SBM. LM21-labelled SBM control sample (E) treated 3 hours in buffer and a LM21-labelled SBM sample (F) after 3 hours treatment with 0.024 FBG enzyme. LM25-labelled SBM control sample $(\mathrm{G})$ treated 3 hours in buffer and a LM25-labelled SBM sample (H) after 3 hours treatment with $0.024 \mathrm{FBG} / \mathrm{ml}$ commercial enzyme. I-L: Immunolabelling and binding of LM5 and LM6 (antibodies to 1-4- $\beta$-D-galactan and 1,5- $\alpha$-L-arabinan, respectively). LM5-labelled SBM control sample (I) treated 3 hours in buffer and a LM5-labelled SBM sample (J) after 3 hours treatment with 0.024 FBG commercial enzyme. LM6-labelled SBM control sample (K) treated 3 hours in buffer and a LM6-labelled SBM sample (L) after treatment with 0.024 FBG commercial enzyme. Bar $=50 \mu \mathrm{m}(\mathrm{A}-\mathrm{L})$. 

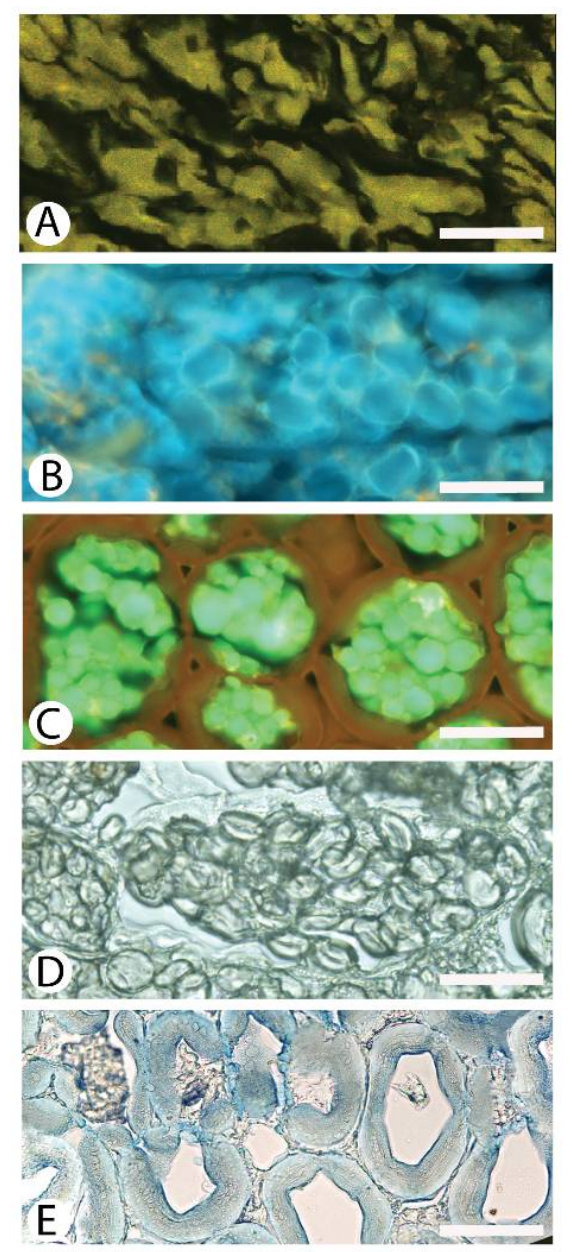

Figure 4. Microscopy controls

Note. A: SBM labelled only with secondary antibody goat $\alpha$-rat Alexa-555 (negative control). B and D: Negative controls for pectin specificity of the dyes. Cell walls of barley grain endosperm are neither stained by coriphosphine $\mathrm{O}$ (B) nor with alcian blue (D). C and E: Positive controls for pectin specificity of the dyes. Cell walls of lupin seed storage cells react strongly to coriphosphine $\mathrm{O}(\mathrm{C})$ and alcian blue (E). Bar $=50 \mu \mathrm{m}$.

\section{Discussion}

The positive effects of NSP degrading enzymes on animal performance, especially in broiler chickens, fed on cereal grains were assumed to be caused by a combination of depolymerisation of viscous arabinoxylans and a degradation of the indigestible cell wall (Le et al., 2013). Viscosity reduction improves nutrient absorption and the degradation of the cell walls improves the liberation of nutrients (e.g. starch and protein) enclosed by the indigestible cell walls (Pettersson \& Åman, 1989; Steenfeldt \& Pettersson, 2001). Single commercial enzymes developed for degradation of type II cereal cell walls are not capable of degrading the complex type I cell wall matrix of SBM. A complex blend of multiple carbohydrases is required to depolymerize the NSPs present in a diet containing SBM due to the diversity and complexity of the cell wall components (Huismann et al., 2003). Successful degradation may lead to improvements in body weight gain, feed conversion efficiency and nutrient digestibility (Slomski, 2010).

The decrease in viscosity using xyloglucan and galactomannan slurries after incubation with the enzyme product (Figure 1) indicates the presence of a xyloglucanase or a xyloglucan active - glucanase and mannase in the product. This in vitro viscosity data agrees well with in vivo studies where inclusion of the enzyme product has been shown to reduce the viscosity of a SBM containing poultry diet, resulting in improvements in litter quality as well as increasing the metabolisable energy content of poultry diets (Kocher et al., 2002).

The non-starch polysaccharide analysis indicated that the enzyme product mediated an efficient solubilisation of 
major insoluble polysaccharide structures containing rhamnose, fucose, arabinose, galactose, glucose and uronic acids (Table 1). Furthermore, viscosity data additionally indicated that soluble xyloglucans and galactomannans may be readily depolymerised by the product. Overall these data indicate the capacity of the enzyme product to depolymerize soluble NSPs as well as mediate solubilisation of the cotyledon cell walls as also was shown by the microscopy techniques employed.

The histochemical dyes coriphosphine $\mathrm{O}$ and alcian blue were used to stain pectin in soybean and SBM (Figure 2). An intense yellow/orange fluorescence from pectins (Sun et al., 2008; Moura et al., 2010; Mosele et al., 2011) was visible in the cell walls of the storage cotyledons cells (Figures 2A and 2B) after staining with coriphosphine O. This corresponds well with the high amount of pectin (mainly rhamnogalaturonans) present in soybeans (Huisman et al., 1998, 2003). Besides being used as a stain for detection of pectin in plant sources (Mosele et al., 2011), coriphosphine $O$ is known to stain other cell components such as DNA and RNA (Mezzanotte et al., 1981) which can also be seen as labelling of nuclei in Figure 2B. Alcian blue is a dye with high affinity for pectic substances (Gunawardena et al., 2007; Arend et al., 2008) and was used to support the results found with coriphosphine $\mathrm{O}$ staining showing pectin solubilisation.

Paraffin embedding for enzyme treatments was chosen (Figures 2C-2M and Figure 3) as sample sections can be de-paraffinated, which enables enzyme access to the sample while other embedding material, such as various resins, may hinder access of enzymes to their substrates. This technique thus allows to clearly detect the enzymatic solubilisation of the substrate occurring over time.

To study the effect of several cell wall degrading enzyme activities in the commercial product on specific cell wall components of soy, commercially available antibodies were used to detect cell wall epitopes (Figures 3A, $3 \mathrm{C}, 3 \mathrm{E}, 3 \mathrm{G}, 3 \mathrm{I}$ and $3 \mathrm{~K}$ ) and loss of antibody binding to cell wall components in SBM after enzyme treatment (Figures 3B, 3D, 3F, 3H, 3J and 3L).

The antibodies to homogalacturonan denoted LM20 generated against Arabidopsis thaliana seed coat mucilage (Verhertbruggen et al., 2009) were used in this study. It should be noted that Arabidopsis thaliana seed coat mucilage consists largely of unbranched rhamnogalacturonan although with homogalacturonan elements (Deng et al., 2006). The solubilisation of pectin by the commercial product, as visualized by loss of coriphosphine $\mathrm{O}$ orange color (Figures $2 \mathrm{C}-2 \mathrm{D}$ and $2 \mathrm{G}-2 \mathrm{H}$ ) as well as loss of epitopes binding to antibody LM20, may actually indicate the presence of rhamnogalacturonase in the product (Figure 3A) since soybeans are assumed to not contain homogalacturonan (Huismann et al., 2001). The antibody LM19 described as an antibody to homogalacturonan was isolated following immunization with an apple fruit pectic galacturonan (47\% galacturonic acid, 34\% xylose, 6\% arabinose, 5\% rhamnose, 4\% galactose) (Verhertbruggen et al., 2009). The fact that apple fruit contains $47 \%$ and $34 \%$ of galacturonic acid and xylose, respectively, the resulting LM19 antibodies elicited may in fact be recognizing xylogalacturonan, which is present in soybean (Huismann et al., 2003; Nakamura et al., 2002) and not homogalacturonan (Huismann et al., 2001). Thus, critical interpretation of data is essential when using commercial antibodies generated towards pectin cell wall components of one plant species and used in experiments to detect their binding to pectin in other plant species which may have another molecular structure. Binding to SBM by xylogalacturonan antibodies developed against pea xylogalacturonan could not be shown in our study (results not shown) and these findings are corroborated by others (Huismann et al., 2003).

The commercially available antibodies also detected cell wall epitopes binding to mannan (LM 21) and xyloglucan (LM 25) and after enzyme treatment these signals were decreased which could be attributed to activity of mannanase and a xyloglucan solubilizing enzyme (Figures 3F and 3H). This data corroborates well with the viscosity data in this study (Figure 1). Treatment with a pure experimental mannanase provided the same results (data not shown) strengthening the assumption that it was mannanase activity in the enzyme product that removed the mannan epitopes. Viscosity and microscopy data indicated the presence of endoglucanases in the multicomponent enzyme. An endoglucanase from Aspergillus niger has not only been shown to degrade glucan but also has a major activity towards xyloglucan (Hasper et al., 2002).

Arabinan and galactan, the side branches of rhamnoglacturonan, could also be detected in SBM (Figures 3I and $3 \mathrm{~K}$ ) in spite of the conditions undergone by the SBM during processing indicating the high resistance of the pectic components to degradation during the heat and solvent treatment in order to extract oil (Pettersson \& Pontoppidan, 2013). The commercial antibody termed as LM21 towards mannan, displays a wide recognition of mannan, glucomannan and galactomannan polysaccharides in several species (Marcus et al., 2010). LM 25, antibody to xyloglucan can also bind to xyloglucan polymers in several species. Likewise the arabinan antibody, LM 5 recognises a linear pentasaccharide in (1-5)- $\alpha$-L-arabinans (Willats et al., 1998) and the galactan antibody, 
LM 6 recognises a linear tetrasaccharide in (1-4)- $\beta$-D-galactans in several species (Willats et al., 1998; Verhertbruggen et al., 2009). As soybean cell wall consists of the above described polysaccharides (Nakamura et al., 2001) binding of the antibodies to the relevant epitopes in the cell walls and their consequent visualisation as well as disappearance after enzyme treatment made it relatively suitable to follow enzyme activity in this study. A better understanding of the chemical structure and location of the different cell wall polysaccharides will lead to an improved understanding of the enzyme specificity required to more efficiently degrade these components. Immunohistochemistry offers a platform for the interpretation of the morphological location of the complex structural carbohydrates and can also be used for monitoring the effect of specific enzyme activities on these structures. Using monoclonal antibodies that bind to specific epitopes in pectins or hemicelluloses can in a simple manner be used to visualize the specific degradation of target carbohydrates. Analyzing the chemical composition of a carbohydrate is fairly easy, but elucidating the structural features and actual substitution pattern is far from straightforward. The intricate structural features of the pectin in soybean cell walls is the reason why these cell walls are quite resistant to enzymatic degradation (Huismann et al., 2003) but in the current study it was shown that the enzyme product could degrade a number of these structures.

\section{Conclusion}

To our knowledge it is the first time that a combination of dietary fibre analysis, viscosity measurements and immunochemical microscopy has been used to elucidate the specific solubilisation and degradation of pectins and several hemicelluloses present in the soybean cell wall using a commercially available multi enzyme product.

Processing of soybean to obtain SBM does not eliminate the binding potential of specific antibodies to the respective epitopes in SBM substrate. The enzyme product solubilised and, most likely, degraded the indigestible carbohydrate fraction which indicates that processing does not alter the structure of this fraction in such a way that it becomes inaccessible for enzymes.

The use of monoclonal antibodies combined with confocal laser scanning microscopy proved to be an efficient tool for the specific visualisation of carbohydrate solubilisation and this technique may prove useful for studying the efficacy of multicomponent cell wall degrading enzymes in the future.

\section{Acknowledgements}

The authors acknowledge Catherine Nielsen and Jozef Mravec, University of Copenhagen for their support and guidance in embedding and sectioning of samples, the Center for Advanced Bioimaging (CAB), University of Copenhagen for collection of Imaging data, Marinus Thingaard Rostved for help with the viscosity measurements, Peter Schimler and Nanna V. Guhle for the NSP and uronic acid data and Dr. Vibe Glitsø for valuable discussions and fine reading of the manuscript.

\section{References}

Ao, T., Cantor, H., Pescatore, A. J., Pierce, J. L., \& Dawson, K. A. (2010). Effects of citric acid, alpha-galactosidase and protease inclusion on in vitro nutrient release from soybean meal and trypsin inhibitor content in raw whole soybeans. Animal Feed Science and Technology, 162, 58-66. http://dx.doi.org/10.1016/j.anifeedsci.2010.08.014

Arend, M., Muninger, M., \& Fromm, J. (2008). Unique occurrence of pectin-like fibrillary cell wall deposits in xylem fibres of poplar. Plant Biology, 10, 763-770. http://dx.doi.org/10.1111/j.1438-8677.2008.00082.x

Brookes, G. (2001). The EU animal feed sector: Protein ingredient use and the implications of the ban on use of meat and bonemeal. Canterbury, UK, Brookes West.

Cowieson, A. J., \& Adeola, O. (2011). BOARD-INVITED REVIEW: Opportunities and challenges in using exogenous enzymes to improve nonruminant animal production. Journal of Animal Science, 89(10), 3189-3218. http://dx.doi.org/10.2527/jas.2010-3715

De Vries, S., Pustjens, A. M., Schols, H. A., Hendriks, W. H., \& Gerrits, W. J. J. (2012). Improving digestive utilization of fiber-rich feedstuffs in pigs and poultry by processing and enzyme technologies: A review. Animal Feed Science and Technology, 178, 123-138. http://dx.doi.org/10.1016/j.anifeedsci.2012.10.004

Deng, C., O’Neill, M. A., \& York, W. S. (2006). Selective chemical depolymerization of rhamnogalacturonans. Carbohydrate Research, 341(4), 474-484. http://dx.doi.org/10.1016/j.carres.2005.12.004

Friedman, M., \& Brandon, D. L. (2001). Nutritional and Health Benefits of Soy Proteins. Journal of Agricultural and Food Chemistry, 49(3), 1069-1086. http://dx.doi.org/10.1016/j.carres.2005.12.004 
Fry, S. C. (1989). The Structure and Functions of Xyloglucan. Journal of Experimental Botany, 40, 1-11. http://dx.doi.org/10.1093/jxb/40.1.1

Gloster, T. M., Ibatullin, F. M., Macauley, K., Eklöf, J. M., Roberts, S., Turkenburg, J. P., ... Davies, G. J. (2007). Characterisation and 3-D structures of two distinct bacterial xyloglucanases from families GH5 and GH12. Journal of Biological Chemistry, 282, 19177-19189. http://dx.doi.org/10.1074/jbc.M700224200

Gunawardena, A. H. L. A. N., Greenwood, J. S., \& Dengler, N. G. (2007). Cell wall degradation and modification during programmed cell death in lace plant, Aponogeton madagascariensis (Aponogetonaceae). American Journal of Botany, 94(7), 1116-1128. http://dx.doi.org/10.3732/ajb.94.7.1116

Hasper, A. A., Dekkers, E., van Mil, M., van De Vondervoort, J., \& de Graaff, L. H. (2002). A new endoglucanase from Aspergillus niger with major activity towards xyloglucan. Applied and Environmental Microbiolphy, 68(4), 1556-1560. http://dx.doi.org/10.1128/AEM.68.4.1556-1560.2002

Huismann, M. M. H., Fransen, C. T. M., Kamerling, J. P., Vligenthart, J. F. G., Schols, H. A., \& Voragen, A. G. J. (2001). The CDTA soluble pectic substances from soybean are composed of rhamnogalacturonan and $\begin{array}{lllll}\text { xylogalacturonan but not homogalacturonan. } & \text { Biopolymers, } & 58,294 .\end{array}$ http://dx.doi.org/10.1002/1097-0282(200103)58:3<279::AID-BIP1005>3.0.CO;2-1

Huismann, M. M. H., Schols, H. A., \& Voragen, A. G. J. (1998). Cell wall polysaccharides from soybean (Glycine max) meal. Isolation and characterisation. Carbohydrate Polymers, 37-87. http://dx.doi.org/10.1016/s0144-8617(97)00111-2

Huismann, M. M. H., Schols, H. A., \& Voragen, A. G. J. (2003). Pectic substances from soybean cell walls distinguish themselves from other plant cell walls pectins. In F. Voragen et al. (Eds.), Advances in Pectin and Pectinase Research (pp. 159-168). http://dx.doi.org/10.1007/978-94-017-0331-4_12

Jones, L., Seymour, G. B., \& Knox, J. P. (1997). Localization of Pectic Galactan in Tomato Cell Walls Using a Monoclonal Antibody Specific to (1[->]4)-[beta]-D-Galactan. Plant Physiology, 113(4), 1405-1412. http://dx.doi.org/10.1104/pp.113.4.1405

Karr-Lilienthal, L. K., Greishop, C. M., Spears, J. K., \& Fahey, G. C. (2005). Amino Acid, Carbohydrate, and Fat Composition of Soybean Meals Prepared at 55 Commercial U.S. Soybean Processing Plants. Journal of Agricultural and Food Chemistry, 53, 2146-2150. http://dx.doi.org/10.1021/jf048385i

Kocher, A., Choct, M., Porter, M. D., \& Broz, J. (2002). Effects of feed enzymes on nutritive value of soyabean meal fed to broilers. British Poultry Science, 43(1), 54-63. http://dx.doi.org/10.1080/00071660120109890.

Langhout, D. J., \& Schütte, J. B. (1996). Nutritional implications of pectins in chicks in relation to esterification and origin of pectins. Poultry Science, 75(10), 1236-42. http://dx.doi.org/10.3382/ps.0751236

Le, D. M., Fojan, P., Azem, E., Pettersson, D., \& Pedersen, N. R. (2013). Visualization of the Anticaging Effect of Ronozyme WX Xylanase on Wheat Substrates. Cereal Chemistry Journal, 90(5), 439-444. http://dx.doi.org/10.2527/jas.53832

Leeds, A. R., Kang, S. S., Low, A. G., \& Sambrook, I. E. (1980). The pig as a model for studies on the mode of action of guar gum in normal and diabetic man. The Proceeding of the Nutrition Society, 39, 44A.

Malathi, V., \& Devegowda, G. (2001). In vitro Evaluation of Nonstarch Polysaccharide Digestibility of Feed Ingredients by Enzymes. Poultry Science, 80, 302-305. http://dx.doi.org/10.1093/ps/80.3.302

Marcus, S. E., Blake, A. W., Benians, T. A. S., Kieran, T. E., Lee, J. D., Poyser, C., ... Knox, J. P. (2010). Restricted access of proteins to mannan polysaccharides in intact plant cell walls. The Plant Journal, 64, 191-203. http://dx.doi.org/10.1111/j.1365-313X.2010.04319.x

Mezzanotte, R., Ferrucci, L., \& Marchi, A. (1981). Methylene-blue/Coriphosphine O/Acridine-Orange, chromosomal DNA and visible light: Interaction and cytological effect in Drosphila melanogaster. Genetica, 55, 203-207. http://dx.doi.org/10.1007/BF00127203

Mosele, M. M., Hansen, A. S, Hansen, M., Schulz, A., \& Martens, H. J. (2011). Proximate composition, histochemical analysis and microstructural localisation of nutrients in immature and mature seeds of marama bean (Tylosema esculentum) - An underutilised food legume. Food Chemistry, 127(4), 1555-1561. http://dx.doi.org/10.1016/j.foodchem.2011.02.017

Moura, E. F., Ventrella, M. C., \& Motoike, S. Y. (2010). Anatomy, histochemistry and ultrastructure of seed and somatic embryo of Acrocomia aculeata (Arecaceae). Scientia Agricola, 67(4), 339-407. http://dx.doi.org/10.1590/S0103-90162010000400004 
Nahashon, S. N., \& Kilonzo-Nthenge, A. K. (2011). Advances in Soybean and Soybean By-Products in Monogastric Nutrition and Health, Soybean and Nutrition. In H. El-Shemy (Ed.), InTech. Retrieved from $\mathrm{http}$ //www.intechopen.com/books/soybean-and-nutrition/advances-in-soybeanand-soybean-by-products-inmonogastric-nutrition-and-health

Nakamura, A., Furuta, H., Maeda, H., Nagamatsu, Y., \& Yoshimoto, A. (2001). Analysis of structural components and molecular construction of soybean soluble polysaccharides by stepwise enzymatic degradation. Bioscience, Biotechnology and Biochemistry, 10, 2249-2258. http://dx.doi.org/10.1271/bbb.65.2249

Nakamura, A., Furuta, H., Maeda, H., Takao, T., \& Nagamatsu, Y. (2002). Analysis of the molecular construction of xylogalacturonan isolated from soluble soybean polysaccharides. Bioscience, Biotechnology and Biochemistry, 66, 1155-1158. http://dx.doi.org/10.1271/bbb.66.1155

Ordaz-Ortiz, J. J., Marcus, S. E., \& Knox, J. P. (2009). Cell wall microstructure analysis implicates hemicellulose polysaccharides in cell adhesion in tomato fruit pericarp parenchyma. Molecular Plant, 2, 910-921. http://dx.doi.org/10.1093/mp/ssp049

Pedersen, H. L., Fangel, J. U., McCleary, B., Ruzanski, C., Rydahl, M. G., Ralet, M.-C., ... Willats, W. G. T. (2012). Versatile high resolution oligosaccharide microarrays for plant glycobiology and cell wall research. Journal of Biological Chemistry, 287, 39429-39438. http://dx.doi.org/10.1074/jbc.M112.396598

Pettersson, D., \& Åman, P. (1989). Enzyme supplementation of a poultry diet containing rye and wheat. British Journal of Nutrition, 62(1), 139-149. http://dx.doi.org/10.1079/BJN19890014

Pettersson, D., \& Pontoppidan, K. (2013). Soybean Meal and the Potential for Upgrading Its Feeding Value by Enzyme Supplementation, Soybean - Bio-Active Compounds. In H. El-Shemy (Ed.), InTech. Retrieved from http://dx.doi.org/10.5772/52607

Sambrook, I. E., \& Rainbird. A. L. (1985). The effect of guar gum and level and source of dietary fat on glucose tolerance in growing pigs. British Journal of Nutrition, 54, 27-35. http://dx.doi.org/10.1079/BJN19850089

Slominski, B. A. (1994). Hydrolysis of galactooligosaccharides by commercial preparations of $\alpha$-galactosidase and B-fructofuranosidase: Potential for use as dietary additives. Journal of the Science of Food and Agriculture, 65, 323 -330. http://dx.doi.org/10.1002/jsfa.2740650310

Slominski, B. A. (2010). Recent Advances in Enzymes for Poultry Diets. Retrieved from $\mathrm{http} / / / \mathrm{www}$. thepoultryfederation.com/public/userfiles/files/2-6\%20Wed\%20-\%20Bogdan\%20Slominski\%2 0-\%20Enzymes\%20for\%20Poultry.pdf

Steenfeldt, S., \& Pettersson, D. (2001). Improvements in nutrient digestibility and performance of broiler chickens fed a wheat-and-rye based diet supplemented with enzymes. Journal of Animal Feed Science, 10, 143-157.

Spurr, A. R. (1969). A low-viscosity epoxy resin embedding medium for electron microscopy. Journal of Ultrasructure Research, 26(1-2), 31-43. http://dx.doi.org/10.1016/S0022-5320(69)90033-1

Sun, Q., Rost, T. L., \& Matthews, M. A. (2008). Wound-induced vascular occlusions in vitis vinifera (vitaceae): Tyloses in summer and gels in winter. American Journal of Botany 95(12), 1498-1505. http://dx.doi.org/10.3732/ajb.0800061

Theander, O., Åman, P., Westerlund, E., Andersson, R., \& Pettersson, D. (1995). Total dietary fibre determined as neutral sugar residues, uronic acid residues and Klason lignin (The Uppsala method): Collaborative study. Journal of AOAC International, 78(4), 1030-1044.

Verhertbruggen, Y., Marcus, S. E., Haeger, H., Ordaz-Ortiz, J. J., \& Knox, J. P. (2009). An extended set of mooclonal antibodies to pectic homogalacturonan. Carbohydrate Research, 344, 1858-1862. http://dx.doi.org/10.1016/j.carres.2008.11.010

Whiteman, P. (1973). The quantitative measurement of Alcian Blue-glycosaminoglycan complexes. Biochemical Journal, 131(2), 343-350.

Willats, W. G., Marcus, S. E., \& Knox, J. P. (1998). Generation of monoclonal antibody specific to (1->5)-alpha-L-arabinan. Carbohydrate Research, 308, 149-152. http://dx.doi.org/10.1016/S0008-6215(98) 00070-6 


\section{Copyrights}

Copyright for this article is retained by the author(s), with first publication rights granted to the journal.

This is an open-access article distributed under the terms and conditions of the Creative Commons Attribution license (http://creativecommons.org/licenses/by/3.0/). 